
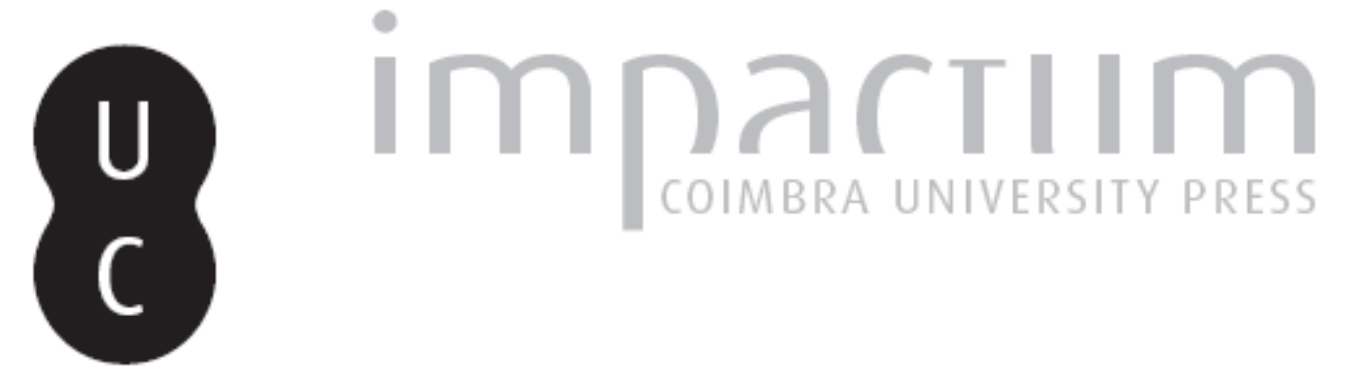

\title{
Rio Mondego e Coimbra: uma longa e ambivalente ligação
}

\section{Autor(es): Rebelo, Fernando}
Publicado por: Faculdade de Letras da Universidade de Coimbra, Instituto de História Económica e Social

URL

persistente:

URI:http://hdl.handle.net/10316.2/28049

DOI:

DOI:http://dx.doi.org/10.14195/0870-4147_43_7

Accessed : $\quad$ 26-Apr-2023 08:35:16

A navegação consulta e descarregamento dos títulos inseridos nas Bibliotecas Digitais UC Digitalis, UC Pombalina e UC Impactum, pressupõem a aceitação plena e sem reservas dos Termos e Condições de Uso destas Bibliotecas Digitais, disponíveis em https://digitalis.uc.pt/pt-pt/termos.

Conforme exposto nos referidos Termos e Condições de Uso, o descarregamento de títulos de acesso restrito requer uma licença válida de autorização devendo o utilizador aceder ao(s) documento(s) a partir de um endereço de IP da instituição detentora da supramencionada licença.

Ao utilizador é apenas permitido o descarregamento para uso pessoal, pelo que o emprego do(s) título(s) descarregado(s) para outro fim, designadamente comercial, carece de autorização do respetivo autor ou editor da obra.

Na medida em que todas as obras da UC Digitalis se encontram protegidas pelo Código do Direito de Autor e Direitos Conexos e demais legislação aplicável, toda a cópia, parcial ou total, deste documento, nos casos em que é legalmente admitida, deverá conter ou fazer-se acompanhar por este aviso.

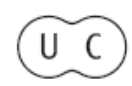





\title{
Rio Mondego e Coimbra - uma longa e ambivalente ligação
}

\author{
FERNANDO REBELO \\ Professor Catedrático da Faculdade de Letras da Universidade de Coimbra \\ Investigador do CEGOT \\ fernandorebelo@gmail.com
}

\section{Resumo:}

Há, indubitavelmente, uma forte ligação entre o Rio Mondego e a cidade de Coimbra. No entanto, quando o Homem se instalou na colina geminada onde depois viria a nascer a cidade, talvez, na sua base, o rio desaguasse numa ria, semelhante às muitas que existiram nas costas europeias, na sequência da transgressão flandriana, e que, no tempo de Afonso Henriques, ainda se poderia comparar com a que Amorim Girão (1922) reconstituiu para o século XI na área de Aveiro. A pouco e pouco, a ria do Mondego foi sendo entulhada por materiais rochosos transportados pelo rio, acabando por desaparecer. A partir de finais do século XIII, as cheias começaram a originar inundações de consequências graves para a ocupação humana, não só pela água transbordada, mas principalmente pelas areias e cascalhos depositados. Desde então, o Homem teve de se adaptar às cheias e inundações, ou a reagir contra elas, com obras, tanto na cidade de Coimbra, como no vale, a montante, ou nas vilas e aldeias da planície aluvial, a jusante (Fernandes Martins, 1940).

Palavras chave:

Coimbra; Mondego; Rias; Cheias; Inundações.
Abstract:

There is undoubtedly a strong connection between the river Mondego and Coimbra. However, when the human population settled on the twin hill where later the city would be raised, perhaps, at the hill's base, the river discharged into a "ria" similar to many that existed in the European coasts, in the wake of the flandrian transgression, and which, in the time of Afonso Henriques, could still be compared to the one outlined by Amorim Girão for the area of Aveiro. Mondego's "ria", however, was gradually obstructed by rocky materials carried by the river and disappeared. From the end of the $13^{\text {th }}$ century on, high waters began to cause floods with serious consequences for human occupation, not only because of the overflowed water, but also and mainly by the sedimentation of sands and gravel. Since then, the population had to adapt to floods and inundations or react against them with building works, both in the city of Coimbra and in the valley upstream, or in small towns and villages of alluvial plain downstream.

Keywords:

Coimbra; Mondego; "Rias"; High waters; Floods. 
1. A origem e grande parte do desenvolvimento da cidade de Coimbra só se compreendem através da presença do Rio Mondego ${ }^{1}$.

No entanto, o Mondego, tal como o conhecemos hoje, resultou de uma longa e complexa evolução em termos de geologia, geomorfologia, climatologia e hidrologia. A geologia poderá explicar como e quando se levantaram os blocos montanhosos que delimitam a bacia do Mondego, tal como a geomorfologia explicará como se formaram as montanhas, os planaltos e os vales relacionados com a sua rede hidrográfica. Por sua vez, a climatologia poderá explicar a sucessão dos tipos de tempo que comandam a formação dos seus caudais, enquanto a hidrologia explicará as variações desses mesmos caudais.

Podemos recuar a tempos cenozóicos não muito recuados, por exemplo, a uns 10 a 20 milhões de anos atrás, e imaginar vários rios percorrendo as áreas por onde corre hoje o Mondego. Sobre uma base cartográfica atual, Suzanne Daveau ${ }^{2}$ reconstituiu antigas direções de drenagem.

Naqueles tempos, o Mondego ainda não existia.

O que é hoje o seu troço inicial, na Serra da Estrela, poderia ser parte do troço inicial de um rio que se dirigisse para o interior da Península. O que é hoje a secção superior do seu vale no planalto da Beira Alta, segundo a reconstituição de Suzanne Daveau, seria certamente um rio que, primeiro, se dirigiria quase em linha reta até ao Atlântico, passando a Norte do Buçaco, mas que depois viria a passar pela bacia da Lousã onde se juntaria com outros rios, seguindo pelo que é hoje parte do vale do Ceira até à área onde veio a nascer a cidade de Coimbra. Só mais tarde, um pequeno rio, que nasceria nas serras do Maciço Marginal, terá acabado por capturar o grande rio que passava a oriente das cristas quartzíticas de Buçaco-Penacova, ajudando a criar o Mondego nosso contemporâneo.

Quando se terão verificado as capturas que conduziram ao curso do Mondego atual? Ocorreram todas nos tempos cenozóicos, que designávamos como Terciário, desde há 65 até há 1,8 milhões de anos ${ }^{3}$ ? Muitas sim, certamente, mas algumas, só depois, já no Quaternário.

Será talvez mais fácil, todavia, saber quando mudou o clima desta região, deixando de ser tropical para ser temperado. Na realidade, os materiais grosseiros de há cerca de 2 milhões de anos, considerados vilafranquianos, tantas vezes

1 Fernando Rebelo, "Condicionalismos físico-geográficos na origem e no desenvolvimento da cidade de Coimbra", Coimbra, Estratégias para o Futuro, Coimbra, Ordem dos Engenheiros, 2002, p. 35-40.

2 Suzanne Daveau, Les Bassins de Lousã et d'Arganil, vol. II, Lisboa, CEG., 1988, p. 298.

3 João Pais, Quadro de divisões estratigráficas, Lisboa, Universidade Nova, 2003. 
chamados depósitos do tipo "raña", poderão corresponder a um período de tempo muito árido, de transição entre os tipos de climas tropicais e os tipos de climas temperados. Foi por cima desses depósitos que, à volta da Cordilheira Central, se organizaram as redes hidrográficas de hoje, embora, em tempos pré-históricos, fossem, pelo menos parcialmente, ainda bem diversas do que são hoje, como se prova com os terraços fluviais existentes. Sucediam-se períodos glaciares e períodos inter-glaciares, os caudais do Mondego e dos seus afluentes variavam e os seus vales aprofundavam-se mais depressa ou mais devagar, consoante a posição do nível do mar e as caraterísticas climáticas da época.

2. O último período frio do Quaternário, o Würm, foi particularmente sentido na Serra da Estrela. Formou-se um glaciar de planalto que chegou a emitir sete línguas ${ }^{5}$, embora nenhuma delas se tivesse relacionado com o Mondego. O máximo da glaciação würmiana terá sido entre há 18 e 20000 anos BP ("before present") e o nível médio das águas do mar terá então recuado para valores que, na Europa ocidental, se supõe terem sido de 100 metros abaixo do nível actual ${ }^{6}$.

Nos seus troços terminais, os rios encaixaram-se em função daquele nível de base. Em território hoje português, o Mondego foi apenas um deles - desde a sua saída do Maciço Marginal de Coimbra (onde hoje se encontram as pontes da Portela) até à foz, em relação ao nível atual, o encaixe foi impressionante, tal como foi sendo comprovado ao longo do séc. XX através de sondagens (cerca de 20 metros na área da cidade, 40 na Adémia, 70 em Montemor-o-Velho e 100 na Figueira da Foz).

O aquecimento climático que terminou com a glaciação do Würm há uns 10-11000 anos BP, quando acompanhado de épocas húmidas, deu-lhe os caudais que permitiram à maior parte do seu vale ir-se aproximando das caraterísticas atuais, mas também esteve na origem da ria em que se transformou o seu tramo final. O nível do Atlântico subiu, pelo que, entrando as suas águas por vales glaciares e por vales fluviais, formaram-se litorais de fiordes e rias. A subida terá sido "rápida" até há 8000 anos BP, tendo, por essa época chegado a -20 metros o nível do mar no norte da França. Foi a chamada transgressão flandriana, que poderá ter atingido o seu máximo há 7000 anos BP. Depois,

4 Orlando Ribeiro, Le Portugal Central.Livret-guide de l'Excursion C, Congrès International de Géographie de Lisbonne, 1949, 180 p. Reimpressão, 1982.

5 Suzanne Daveau, "La glaciation de la Serra da Estrela", Finisterra, 6 (11), 1971, p. 5-40.

6 J. J.Lowe \& M. J. C. Walker, Reconstructing Quaternary Environments, Harlow, Longman, 1984, 389 p; Jean Chaline, Histoire de l'Homme et des Climats au Quaternaire, Paris, Doin, 1985 , 366 p.; Suzanne Daveau, "A Cordilheira Central”. O Relevo de Portugal. Grandes Unidades Regionais, Coimbra, Associação Portuguesa de Geomorfólogos, 2004, p. 75-96. 
admite-se a existência de avanços e recuos até há 2000 anos $\mathrm{BP}^{7}$. Podemos, portanto, aceitar um litoral de rias em Portugal, ou seja, conforme a definição de Friederich von Richtoffen, um litoral onde a água do mar entrava pelos antigos vales fluviais. Entre elas, conhece-se bem a ria de Aveiro e a sua evolução ${ }^{8}$. Sendo o rio Mondego mais importante do que o Vouga, é natural que a ria do Mondego tenha banhado a área onde se instalou a cidade de Aeminium.

3. Esta cidade romana, que veio a estar na base de Coimbra ${ }^{9}$, começou por aproveitar um espaço no cimo da colina geminada sobranceira ao rio (ou talvez mesmo à ria), no local onde existira uma povoação anterior, nas proximidades da área onde seria mais fácil a sua travessia durante grande parte do ano. Para montante do que é hoje a Portela, no bloco xistoso levantado do Maciço Marginal, o vale, demasiado estreito, dificultava a travessia, muito em especial no inverno; para jusante, a ria, como mais tarde o rio com a sua planície aluvial, também criavam dificuldades ${ }^{10}$. Entretanto, a cidade foi descendo a colina para oeste até ao que seria um terraço ante-wurmiano debruçado sobre o Mondego que, por ali, tinha a sua foz na ria.

Entre aproximadamente 300 anos antes de Cristo e 400 depois de Cristo pode falar-se de reaquecimento climático na Europa ${ }^{11}$. Talvez tenha sido, em grande parte, por causa disso que o Império Romano se estendeu tanto para Norte, só construindo uma muralha (a Muralha de Adriano) já perto da Escócia. Depois, não foram só os ataques dos guerreiros ditos bárbaros que fizeram cair o Império. $\mathrm{O}$ arrefecimento foi-se instalando, os glaciares avançaram nas montanhas europeias, enquanto os rios passaram a apresentar caudais muito reduzidos durante o inverno. Em Portugal, nunca mais regressaram os glaciares, mas o arrefecimento certamente também se fez sentir. O mar poderá ter recuado um pouco e, no caso do Mondego, a ria deverá ter começado a ser entulhada progressiva e discretamente por materiais transportados pelo Mondego e outros rios locais, hoje seus afluentes.

7 J. J. Lowe \& M. J. C. Walker, Reconstructing..., cit.; Jean Chaline, Histoire..., cit.

8 Amorim Girão, A Bacia do Vouga. Estudo geográfico, Coimbra, Imprensa da Universidade, 1922, 190 p.; Fernando Rebelo, "O risco de sedimentação na laguna de Aveiro: leitura actual de um texto de Amorim Girão (1922)", Territorium, 14, 2007, p. 63-69.

9 Jorge de Alarcão, Coimbra. A montagem do cenário urbano, Coimbra, Imprensa da Universidade, 2008, 308 p.

${ }^{10}$ Fernando Rebelo, "Nota sobre o conhecimento geomorfológico da área de Coimbra". Memórias e Notícias, Publ. Mus. Lab. Mineral. Geol. Univ. Coimbra, 100, 1985, p. 193-202.

${ }^{11}$ Jean Chaline, Histoire..., cit. 
A partir de 750 e até ao séc. XI, os tempos voltaram a ser quentes. Supõe-se que tenham sido ainda mais quentes do que os do Império Romano. Na verdade, os glaciares desapareceram da Gronelândia. Os Vikings estabeleceram-se lá e, como não havia icebergs tornou-se possível viajar até à América do Norte, então descoberta por Leif Ericson, filho de Eric o Vermelho ${ }^{12}$. Quanto ao caso que nos ocupa, não é provável que uma subida do nível do mar tenha feito muito mais do que acumular areia num hipotético "cabedelo" da hipotética foz do Mondego na sua ria.

4. Assim seria ainda no séc. XI, quando, uns $50 \mathrm{~km}$ a norte, como mostrou Amorim Girão ${ }^{13}$, a ria de Aveiro existia em verdadeira plenitude. O seu mapa de reconstituição da ria de Aveiro no séc. XI autoriza-nos a pensar numa situação paralela para a ria do Mondego na mesma época. Dificilmente se provará que a ria tenha chegado à área da Portela, embora tal hipótese não deixe de poder colocar-se. Mas quem hoje observe o que se passa na foz dos rios que desaguam em muitas rias do Norte da Península Ibérica ou dos rios que desaguam em muitos fiordes da Noruega e da Irlanda, imagina bem o momento em que o Mondego desaguaria na área do Arnado, com uma espécie de "cabedelo". Parte das areias e dos níveis argilosos mais profundos aí existentes poderão ser disso a prova. Muito possivelmente, enquanto a ria chegou à área de Coimbra, os barcos de mar navegariam sem grandes problemas até aí e com facilidade aí atracariam ${ }^{14}$. No tempo de D. Afonso Henriques, no século XII, não parece que se colocassem problemas de inundações quando se construiu a Igreja de Santa Cruz, na margem direita do Mondego, fora das muralhas da cidade. Alfredo Fernandes Martins ${ }^{15}$ sublinhou que "conforme as palavras de Frei Luiz de Sousa, na História de S. Domingos, quando se referia à fundação do convento (igualmente) na margem direita sob a invocação daquele santo, o Mondego corria alcantilado e profundo no século XIII". Também não se consegue compreender a fundação do Mosteiro de Santa Clara, sem pensar numa forma de vale assim ${ }^{16}$.

12 Jean Chaline, Histoire..., cit.

${ }^{13}$ Amorim Girão, A Bacia ..., cit.

${ }^{14}$ No foral de Penacova, de Dezembro de 1192, lê-se: "Até ao mês de Maio dêem a décima dos peixes de mar que trouxerem pelo Mondego.".

${ }^{15}$ Alfredo Fernandes Martins, O Esforço do Homem na Bacia do Mondego, Coimbra, ed. Autor, 1940, 299 p.

${ }^{16}$ Ver Ana Paula Pratas Santos, A Fundação do Mosteiro de Santa Clara de Coimbra (da Instituição por D. Mor Dias à intervenção da Rainha Santa Isabel), Coimbra (versão policopiada), vol. II, apêndice documental, p. 239-241. A 3 de Setembro de 1316, em Coimbra, a prioresa 
Uma pequena idade do gelo, que se manifestou na Europa entre o século XII e o século XIV, não terá sido suficientemente longa para modificar o que, todavia, já estava em andamento - o entulhamento das rias.

O risco da ocorrência de cheias no Mondego começara a manifestar-se ainda no século XIII, mas o rio só se terá tornado perigoso, com grandes e frequentes cheias, provocando, por vezes, extensas inundações, devido ao entulhamento total da antiga ria, durante e depois do período quente dos sécs. XIV a XVI, não mais deixando de o ser.

Os caudais do Mondego foram certamente afetados pela alternância de períodos de aquecimento e de arrefecimento climático, mas as cheias sempre existiram dadas as características torrenciais da sua bacia hidrográfica. $\mathrm{Na}$ realidade, para a explicação do funcionamento do Rio Mondego, mais importantes do que as mudanças climáticas de pormenor são as características geomorfológicas da bacia hidrográfica, que, perante um clima mediterrâneo, melhor definido nos períodos mais quentes, o transformam numa grande torrente. Muitas vezes, teve cheias catastróficas. A elas se ficou a dever o progressivo aumento da espessura e da largura da planície aluvial, em construção desde a saída do vale apertado da travessia do Maciço Marginal, na área da foz do Ceira, até ao mar aberto, na proximidade do qual, entretanto, nascera a Figueira da Foz.

Perderam-se igrejas, casas, aldeias inteiras, na planície. Foi necessário abrir valas de drenagem e secar pântanos ${ }^{17}$. Em Coimbra, na margem esquerda,

D. Inês Peres e o convento de Santa Ana de Coimbra fazem publicar uma carta dirigida a D. Estêvão, bispo de Lisboa e conservador dos privilégios da Ordem dos Frades Menores e Clarissas, não datada, necessariamente anterior àquela data e posterior a Outubro de 1312 (altura em que Frei Estêvão de Santarém se tornou Bispo de Lisboa), cujo sumário apresentado por Ana Paula Pratas Santos é o seguinte: "a prioresa D. Inês Peres e o convento de Santa Ana de Coimbra fazem publicar uma carta dirigida a D. Estêvão, bispo de Lisboa e conservador dos privilégios da Ordem dos Frades Menores e Clarissas, afirmando não ser sua intenção retirar a interposição que lhes lançaram pela postura que ele assumiu a favor dos frades menores e das clarissas de Coimbra, por causa da mudança da casa delas, e ainda lhe comunicam que renovam a sua apelação à Sé Apostólica.” Entre outros motivos justificativos da sua mudança para o local que passara a ser dos frades menores, as freiras referem terem-no feito porque na casa em que se haviam recolhido correram "perigo de morte" por causa das "inundações", "naquele tempo em que cresceu o rio", acrescentando que o novo local por elas escolhido fora a "arca de Deus porque nesse tempo não poderiam habitar comodamente o local por elas inicialmente escolhido", e que era muito próximo àquele onde foi fundado Santa Clara. Ora, pelas datas de fundação e de refundação deste (1286, primeira pedra da primeira fundação e 1316, início das obras da rainha D. Isabel), nos finais do séc. XIII já eram bem conhecidos os problemas do local.

${ }^{17}$ Maria Helena da Cruz Coelho, O Baixo Mondego nos finais da Idade Média, $2^{\mathrm{a}}$ ed., Lisboa, 1989, INCM. 
no séc. XVII, foi necessário construir um novo Mosteiro de Santa Clara ${ }^{18}$, no cimo da vertente, afastado das áreas inundáveis. Na margem direita, o acesso ao interior da Igreja de Santa Cruz fazia-se subindo quatro degraus de escada; na primeira metade do século XX, passou a ser necessário descer sete ${ }^{19}$.

5. A cidade foi crescendo em diálogo com o Mondego, temendo as suas cheias, e aproveitando velhos espaços do antigo leito, como alguns terraços e, mais recentemente, o vale abandonado de um antigo meandro, o da Arregaça, além das vertentes e da própria planície aluvial.

Segundo A. Fernandes Martins ${ }^{20}$, os caudais do Mondego, em Coimbra, no início do séc. XX, oscilariam entre 0 e $3000 \mathrm{~m}^{3}$ por segundo. Não tinham chegado ainda os tempos quentes da década de 1940-1950. Na grande cheia de 1948 , terão ultrapassado os $4000 \mathrm{~m}^{3} / \mathrm{s}\left(4167 \mathrm{~m}^{3} / \mathrm{s}\right.$, na Ponte de Santa Clara), de acordo com os cálculos de J. A. Sá Marques, P. Amado Mendes e F. Seabra Santos ${ }^{21}$.

Porquê estas cheias e inundações? A bacia hidrográfica do Mondego estende-se pelo centro de Portugal numa área onde se encontra um clima muito mal compreendido, o clima temperado mediterrâneo. Tal como era definido há um século atrás pelo grande geógrafo francês Emmanuel de Martonne ${ }^{22}$ (1909), é um clima em que as chuvas ocorrem principalmente na época fresca, verificando-se uma maior ou menor secura estival. No entanto, a variabilidade dos principais elementos climáticos, especialmente as temperaturas e as precipitações, no tempo e no espaço é um facto bem conhecido dos geógrafos, podendo haver grandes diferenças de um ano para outro, tal como entre lugares relativamente próximos. No caso concreto da bacia hidrográfica do Mondego, o clima mediterrâneo está bem definido nas terras baixas ao longo de todo o ano, mas, nas terras altas, apresenta-se bem definido apenas no verão; aí, as temperaturas descem muito no inverno e as chuvas são abundantes. Na Cordilheira Central, o efeito da altitude é notório no que respeita à precipitação - a Serra da Estrela

${ }^{18}$ Pedro Dias, Coimbra. Arte e História, Coimbra, FLUC, Instituto de História da Arte, $2^{\text {a }}$ edição, revista e aumentada, 1988.

${ }_{19}$ Alfredo Fernandes Martins, O Esforço..., cit.

${ }^{20}$ Idem.

${ }^{21}$ J. A. Sá Marques; P. Amado Mendes; F. Seabra Santos, "Cheias em áreas urbanas: a zona de intervenção do Programa Polis em Coimbra”, Territorium, 12, 2005, p. 29-53.

${ }^{22}$ Emmanuel de Martonne, Traité de Géographie Physique, 1909. Tradução portuguesa das edições de 1948 (I tomo) e 1951 (II tomo): Lisboa, Cosmos, Panorama da Geografia, Vol. I, $1953,954 \mathrm{p}$. 
regista uma média anual superior a 2500 mm, segundo Amorim Girão ${ }^{23}$ (1941 e 1958), confirmada por Suzanne Daveau ${ }^{24}$ (1977).

A bacia hidrográfica do Mondego, que ocupa uma superfície de $6670 \mathrm{Km}^{2}$, tem como rios principais, com resposta rápida às precipitações intensas, rios provenientes da Cordilheira Central, com caraterísticas torrenciais. É o caso do próprio Rio Mondego, cujas cabeceiras se localizam na Serra da Estrela, com o ponto mais alto a $1547 \mathrm{~m}$ de altitude. No total, o Mondego tem apenas $227 \mathrm{~km}$ de comprimento - no início da sua planície aluvial, junto a Coimbra, pouco mais tem do que 180 . O seu afluente Alva apresenta as cabeceiras também na Serra da Estrela, mas a maior altitude ( $1651 \mathrm{~m})$, e é menos extenso $(115 \mathrm{~km})$ - aproxima-se ainda mais da definição de uma torrente do Mediterrâneo. Como provou Luciano Lourenço (1989), o Alva apresenta "elevada torrencialidade", sendo que o seu "regime se poderá definir como muito contrastado do tipo pluvial mediterrâneo" 25 (p. 145). No entanto, o Mondego recebe, também, rios regionalmente importantes como o Dão, que drena (indirectamente) a Serra do Caramulo, e o Ceira, proveniente das montanhas de xisto da Cordilheira Central (com origem a uma altitude de cerca de $1500 \mathrm{~m}$ ) e que, depois de drenar a bacia da Lousã e atravessar o Maciço Marginal, recebe o Dueça, que, por sua vez, drena a extremidade ocidental da Cordilheira Central e parte das Serras Calcárias do Maciço de Sicó. O Ceira vem confluir com o Mondego a montante da cidade de Coimbra, assim contribuindo e, por vezes, de modo significativo, para as inundações na área urbana.

Construída nos anos 70 do século XX e em funcionamento desde 1982, a barragem da Aguieira, situada cerca de $40 \mathrm{~km}$ a montante de Coimbra, controla os caudais do Mondego e do Dão. Pouco antes de chegar à sua foz no Mondego, a jusante da Aguieira, o Alva teve também os seus caudais controlados por uma barragem (Fronhas), entretanto construída. As caraterísticas torrenciais destes rios conduzem à subida rápida das suas águas em situações meteorológicas originadoras de precipitações intensas, especialmente quando ocorrem sobre solos já saturados por chuvas anteriores. Estas caraterísticas, associadas ao tipo de material rochoso de grande parte da bacia hidrográfica, com afloramentos de granitos, por vezes muito alterados, e mesmo de rochas gresosas, também

${ }^{23}$ Amorim Girão, Atlas de Portugal, Coimbra, IEG. $2^{\text {a }}$ edição, revista e aumentada, 1958 ( $1^{\mathrm{a}}$ ed. 1941).

${ }^{24}$ Suzanne Daveau, Répartition et Rythme des Précipitations au Portugal. Lisboa, CEG, $1977,192 \mathrm{p}$.

${ }^{25}$ Luciano Lourenço, O Rio Alva - Hidrogeologia, Geomorfologia, Climatologia, Hidrologia, Coimbra, Instituto de Estudos Geográficos, Faculdade de Letras, 1989, 162 p. 
acarretam a deposição de carga sólida a montante das barragens, o que de ano para ano vai reduzindo a capacidade de água retida. A necessidade de abertura das comportas das barragens a partir de certo momento e ainda o facto de os caudais do Ceira não estarem controlados foram factos decisivos na manifestação do risco de cheia e consequentes inundações na área de Coimbra, no inverno de 2000/200126.

A jusante da cidade de Coimbra, podem contribuir para as inundações dos campos do Mondego alguns pequenos afluentes - Ribeira de Ançã e Rio Foja, pela margem direita, tal como Ribeira de Cernache, Rio da Ega, Rio Arunca e Rio do Pranto, pela margem esquerda. No entanto, a maior parte das vezes, quase todos eles funcionam como digitações do Mondego, ficando as suas planícies inundadas pela entrada das águas do rio principal.

Com um clima mediterrâneo bem definido (Csa, aplicando a tabela classificativa de W. Koeppen ${ }^{27}$ ) e com uma topografia acidentada, Coimbra foi crescendo, não só sobre a planície aluvial do Mondego, mas também sobre bacias de recepção, canais de escoamento e cones de dejecção de pequenas torrentes ${ }^{28}$ que sempre criaram problemas erosivos graves (desgaste, transporte e deposição) - o Mondego era o seu nível de base local.

Concluindo: pelas condições de navegabilidade, tanto o Mondego, como a ria, onde desaguava provavelmente ainda no período quente dos séculos VIII a XI, foram determinantes para a localização e para uma primeira fase do desenvolvimento de Coimbra. No entanto, a evolução hidrogeomorfológica da Bacia do Mondego, ao longo dos últimos séculos, gerando cheias potenciadoras de inundações, que além das águas traziam igualmente carga sólida a ruas e campos, veio criar problemas, não só a cidade, mas também a toda a região. De uma forma ou de outra, o Homem, de acordo com a tecnologia de que dispunha em cada momento histórico, foi tentando defender-se da fúria das suas cheias; não podendo vencê-las, muitas vezes teve de se afastar das áreas de risco, construindo edifícios em sítios mais ou menos afastados dos anteriores. Assim se ia alargando o espaço urbano. Na verdade, o tão procurado domínio do Mondego pelo Homem nunca foi além de uma vitória passageira. O inverno

${ }^{26}$ Pedro Proença Cunha, "Vulnerabilidade e risco resultante da ocupação de uma planície fluvial - o exemplo das cheias do rio Mondego (Portugal central), no Inverno de 2000/2001", Territorium, 9, 2002, p. 13-35.

${ }^{27}$ W. Koeppen, Die Klima der Erde. Berlin, De Gruyter, Tradução castelhana: Climatologia, México, Fondo de Cultura, 1923.

${ }^{28}$ Fernando Rebelo, Riscos Naturais e Acção Antrópica. Coimbra, Imprensa da Universidade, 2001, 274 p. ( $2^{\text {a }}$ edição, revista e aumentada, 2003). 
de 2000/2001, com as cheias e inundações que provocou, 19 anos depois da entrada em funcionamento da Barragem da Aguieira, pode bem considerar-se a prova que ainda faltava.

Recebido: 04/11/12

Aceite: 09/04/12 